\title{
Analysis on the $\mathrm{T}_{c}$ Values of $\mathrm{MPB} \mathrm{Pb}\left(\mathrm{Zr}_{1-\mathrm{x}} \mathrm{Ti}_{\mathrm{x}}\right) \mathrm{O}_{3}$ Ferroelectric Ceramics
}

\author{
Balgovind Tiwari ${ }^{1}$, T. Babu ${ }^{2}$, R.N.P. Choudhary ${ }^{3}$ \\ ${ }^{1}$ Assistant Professor, Dept. of Physics, IIIT-RKValley, RGUKT, A.P., India \\ ${ }^{2}$ Teacher, Dept. of Physics, Sri Chaitanya High School, Vempalli, Kadapa, A.P., India \\ ${ }^{3}$ Professor, Dept. of Physics, ITER-SOA University, Bhubaneswar, Orissa, India \\ balgovindtiwari@gmail.com
}

\section{Abstract}

In this communication an attempt has been made to review, in brief, on Curie temperatures $\left(T_{c}\right)$ of lead zirconatetitanate near morphotropical phase boundary. This review also includes 52/48 PZT modified by cadmium $\left(\mathrm{Cd}^{+2}\right)$ in various amounts such as $5 \%, 10 \%$, and $15 \%$. We are proposing an easy method of selecting a substitution element for synthesizing modified lead zirconatetitanate (PZT) ceramics. Our investigation revealed that substitution of +3 valence elements will enhance $T_{c}$ values whereas the substitution of +2 valence elements will decrease $T_{c}$. The change in $T_{c}$ values is also attributed to ionic radii of modifier ions.

Keywords: PZT, Ceramic, MPB, $T_{c}$, Ionic Radius

\section{Introduction}

PZT is an inorganic ferroelectric oxide with perovskite $\left(\mathrm{ABO}_{3}\right)$ structure. It is formed by the combination of lead zirconate $\left(\mathrm{PbZrO}_{3}, \mathrm{~T}_{\mathrm{c}}=490\right.$ ${ }^{\circ} \mathrm{C}$ ) and lead titanate $\left(\mathrm{PbTiO}_{3}, \mathrm{~T}_{\mathrm{c}}=230{ }^{\circ} \mathrm{C}\right)$ crystalline solids. Its unit cell consists of lead $\left(\mathrm{Pb}^{+2}\right)$ atoms at the A-site and zirconium/titanium $\left(\mathrm{Zr}^{+4} / \mathrm{Ti}^{+4}\right)$ atoms at the B-site (Figure1) [1-2].It is being used widely in several technological applications such as non-volatile memories (due to decent hysteresis properties) [3-4], piezoelectric micromacahined ultrasonic transducers (due to lateral strain generated by piezoelectricity) [5-6], micromachined bimorph energy harvester (due to high efficiency in power conversion) [7], hard disk drives (for detecting hard on media) [8], sensors (due to capacitance) [9], etc. Due to the superior physical properties, PZT plays a significant role in the above mentioned applications.

The physical properties of PZT can be varied depending on the type of application. For instance, in the case of fuel injection actuators and shock sensors, high $\varepsilon_{r}$ and $T_{c}$ are required. In contrast, low $\varepsilon_{r}$ is strongly needed for inkjet actuator and loudspeaker applications [10]. Fabrication of capacitors and ultrasonic transducers require materials with high dielectric constant and large coefficient of electromechanical coupling [11]. So tuning the physical properties of PZT is very much necessary to meet the requirements of the above mentioned applications. There are two major ways to alter the physical properties of PZT: (1) varying the $\mathrm{Zr} / \mathrm{Ti}$ ratio, (2) substitution of suitable elements at $\mathrm{A}$ and/or B sites (i.e. cation sites) [12]. PZT ceramics with numerous compositions $\left(P b\left(Z r_{1-x} T i_{x}\right)\right.$ where $\left.0<x<100\right)$ can be synthesized through various preparation techniques such as solid state synthesis, RF magnetron sputtering, sol-gel method, etc. Further, the physical properties of the possible PZT composition can be modified in two ways: (1) substitution of the acceptor elements, (2) substitution of the donor elements [10]. Elements are considered as the donors only when their valence is greater than +2 or +4 and are substituted at $\mathrm{A}$ or $\mathrm{B}$ sites respectively. Elements are known 
www.rspsciencehub.com

as acceptors whose valence is less than +2 or +4 and are substituted at A or B sites respectively [3, 13-18].

In any PZT composition, if the amount of titanium is high then the material shows the phase of tetragonal structure. When the zirconium content is high, it shows the phase of rhombohedral structure. Near morphotropical phase boundary (MPB), both tetragonal and rhombohedral phases coexist together. The coexistence of these phases has been attributed to the high value of coefficient of electromechanical coupling. But in 1999, just below the MPB presence of monoclinic phase which is intermediate between tetragonal and rhombohedral is observed. Due to the extensive physical properties, PZT near MPB is widely investigated ferroelectric ceramic material system. Therefore in this work, we have synthesized PZT of MPB composition and modified it with $\mathrm{Cd}$ by replacing lead. We present the effect of $\mathrm{Cd}^{+2}$ ions substitution on the $\mathrm{T}_{\mathrm{c}}$ of PZT. Also presented is the analysis on $T_{c}$ values of MPB PZT ceramics due to the substitution of +2 and +3 valence elements.

\section{Experimental Section}

The oxides of high purity such as lead oxide (99.9\%, M/S. LobaChemiePvt. Ltd., India), zirconium dioxide $(99.9 \%, \mathrm{M} / \mathrm{S}$. Sarabhai Chemicals, India), titanium dioxide $(99.9 \%, \mathrm{M} / \mathrm{S}$. LobaChemiePvt. Ltd., India), and cadmium oxide (99.9\%, M/S. LobaChemiePvt. Ltd., India) have been used to prepare the samples. The samples of PCZT $\left(\mathrm{Pb}_{1-\mathrm{x}} \mathrm{Cd}_{\mathrm{x}}\left(\mathrm{Zr}_{0.52} \mathrm{Ti}_{0.48}\right) \mathrm{O}_{3}, \mathrm{x}=0.00,0.05\right.$, $0.10,0.15)$ have been prepared by solid state route. The detailed step by step procedure and the complete process parameters are similar to that which has been reported elsewhere [14-16]. The experimental condition for calcination of powders: $950{ }^{\circ} \mathrm{C}$ for 6 hours in air atmosphere. The experimental condition for sintering of pellets: $1100{ }^{\circ} \mathrm{C}$ for 4 hours in alumina crucibles. A detailed method of extracting the electrical measurements has been reported elsewhere [14].

\section{Results and Discussion}

\subsection{Study of temperature dependent dielectric constant}

Figure 2 shows the variation of dielectric constant $\left(\varepsilon_{\mathrm{r}}\right)$ of PCZT ceramics with temperature.
Volume 02 Issue 09 September 2020

For all samples, $\varepsilon_{r}$ value increased with increase in temperature up to its maximum value $\left(\varepsilon_{\max }\right)$ and then showed a decrease at all frequencies except at $1 \mathrm{kHz}$ where a further increase has been observed. Space charge polarization(scattering/transportation of space charges due to thermal activation) or some defects may be responsible for the increase of $\varepsilon_{r}$ at higher temperatures [17-18].
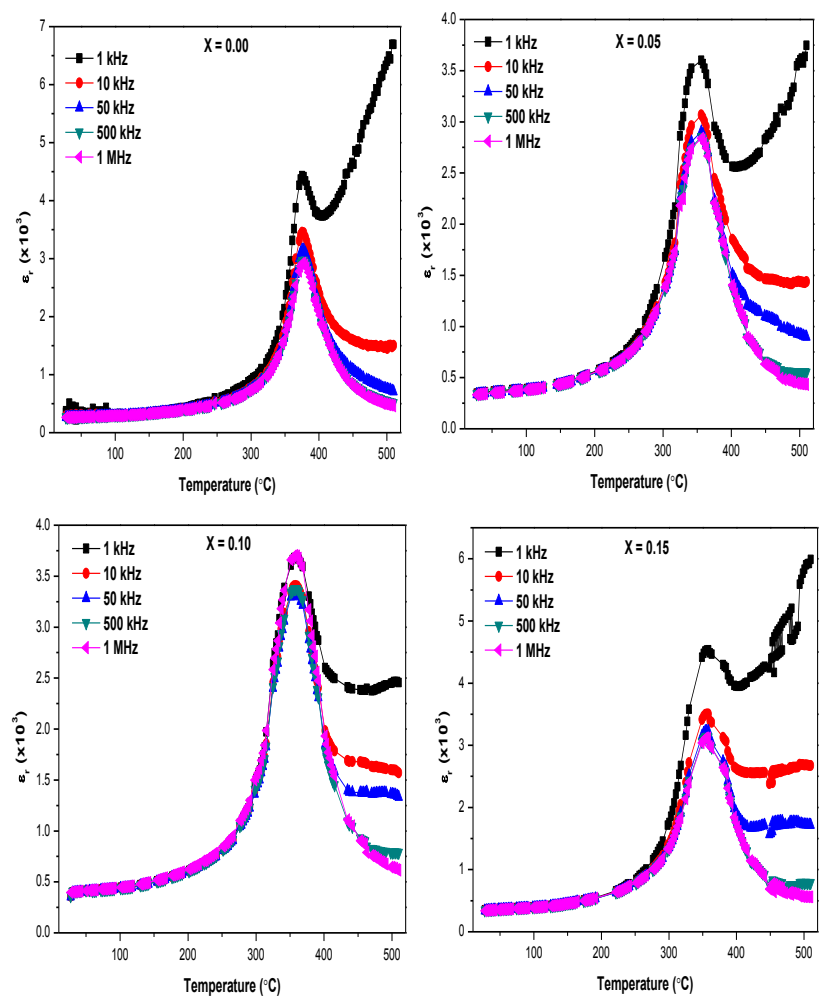

\section{Fig.1. Variation of dielectric constant with temperature}

It is observed from the figure that there is a point of Curie temperature $\left(T_{c}\right)$ at which the transition of phase has been occurred. The occurrence of phase transition is generally from the ferroelectric to non-ferroelectric phase (paraelectric phase).[2732] In each composition, an identical $T_{c}$ has been observed at the given frequencies (value of $\mathrm{T}_{\mathrm{c}}$ has not changed much with change in frequency). The change in the value of $\mathrm{T}_{\mathrm{c}}$ is due to the $\mathrm{Cd}$ substitution at the $\mathrm{Pb}$-site. Substitution of $5 \%$ amount of $\mathrm{Cd}$ has decreased the value of $\mathrm{T}_{\mathrm{c}}$ from $375{ }^{\circ} \mathrm{C}$ to $356{ }^{\circ} \mathrm{C}$ where the further increase in the concentration of $\mathrm{Cd}$ has not changed much the value of $\mathrm{T}_{\mathrm{c}}$. The decrease in value of $\varepsilon_{\max }$ with increase in frequency has been clearly observed in $\mathrm{x}=0.00,0.05,0.15$ samples, indicating the presence of normal dielectric behaviour of a 
www.rspsciencehub.com

ferroelectric material [19]. But for $\mathrm{x}=0.10$ sample, an initial decrease followed by constancy in the value of $\varepsilon_{\max }$ is observed. Widened dielectric peaks were not observed in the samples, suggesting the absence of disordering in the material perovskite structure. This means that all the cations are arranged orderly in the material system.

3.2 Effect Substitution of +2 and +3 Valence Elements by Replacing Lead

$\mathrm{T}_{\mathrm{c}}$ is a specific temperature that helps to identify the phase transition of ferroelectric materials from the ferroelectric to the non-ferroelectric phase. This value of PZT will be maximum at MPB due to the high polarization of material [20-26]. The $T_{c}$ values of modified MPB PZT ceramics are given in Table 1.1 in continuation with the use of Table 1 , and in Table 2.2 in continuation with the use of Table 2.

Table.1. $T_{c}$ Values of MPB PZT Ceramics due to +3 Valence Modifiers Substitution

\begin{tabular}{|c|c|c|c|c|c|c|}
\hline $\begin{array}{l}\mathbf{S} . \\
\mathbf{N}\end{array}$ & Composition & $\begin{array}{l}\text { Modifier (of }+3 \\
\text { Valence) }\end{array}$ & \multicolumn{4}{|c|}{$\begin{array}{l}\text { Concentration of } \\
\text { Modifier }(\%)\end{array}$} \\
\hline 1 & $\mathrm{PZ}_{48} \mathrm{~T}_{52}$ & Gallium & 0 & \multicolumn{3}{|l|}{6} \\
\hline 2 & $\mathrm{PZ}_{52} \mathrm{~T}_{48}$ & Lanthanum & 0 & \multicolumn{3}{|l|}{2} \\
\hline 3 & $\mathrm{PZ}_{52} \mathrm{~T}_{48}$ & Neodymium & 0 & \multicolumn{3}{|l|}{2} \\
\hline 4 & $\mathrm{PZ}_{52} \mathrm{~T}_{48}$ & Dysprosium & 0 & \multicolumn{3}{|l|}{2} \\
\hline 5 & $\mathrm{PZ}_{50} \mathrm{~T}_{50}$ & Bismuth & 2 & 13 & 27 & \\
\hline 6 & $\mathrm{PZ}_{52} \mathrm{~T}_{48}$ & Ytterbium & 0 & \multicolumn{3}{|l|}{5} \\
\hline 7 & $\mathrm{PZ}_{55} \mathrm{~T}_{45}$ & Gadolinium & 0 & 6 & \multicolumn{2}{|l|}{9} \\
\hline 8 & $\mathrm{PZ}_{55} \mathrm{~T}_{45}$ & $\begin{array}{l}\text { Lanthanum \& } \\
\text { Bismuth }\end{array}$ & 0 & 3 & 5 & 7 \\
\hline
\end{tabular}

Table.1.1. $T_{c}$ Values of MPB PZT Ceramics (continuation to Table 1)

\begin{tabular}{|c|c|c|c|c|}
\hline \multicolumn{4}{|c|}{$\mathbf{T}_{\mathrm{c}}\left(\sim^{\circ} \mathbf{C}\right)$} & Reference \\
\hline \multicolumn{2}{|l|}{385} & \multicolumn{2}{|l|}{432} & 21 \\
\hline \multicolumn{2}{|l|}{323} & \multicolumn{2}{|l|}{353} & 22,23 \\
\hline \multicolumn{2}{|l|}{323} & \multicolumn{2}{|l|}{325} & 22,24 \\
\hline \multicolumn{2}{|l|}{323} & \multicolumn{2}{|l|}{275} & 22,24 \\
\hline 405 & 410 & \multicolumn{2}{|l|}{450} & 25 \\
\hline \multicolumn{2}{|l|}{323} & \multicolumn{2}{|l|}{393} & 22,26 \\
\hline 380 & 410 & \multicolumn{2}{|l|}{420} & 27 \\
\hline 457 & 542 & 545 & 548 & 28 \\
\hline
\end{tabular}

Volume 02 Issue 09 September 2020

The increment/decrement in $T_{c}$ is found to be dependent on the valence of the modifier. The $T_{c}$ values are increased when ceramics were modified with +3 valence ions. But when the ceramics were modified with +2 valence ions, the $T_{c}$ values are decreased.

Table.2. $T_{C}$ Values of MPB PZT Ceramics due to +2 Valence Modifiers Substitution

\begin{tabular}{|c|c|c|c|c|c|c|}
\hline $\begin{array}{l}\mathbf{S} \\
\mathbf{N}\end{array}$ & Composition & $\begin{array}{l}\text { Modifier (of } \\
+2 \text { Valence) }\end{array}$ & \multicolumn{4}{|c|}{$\begin{array}{l}\text { Concentration of } \\
\text { Modifier }(\%)\end{array}$} \\
\hline 1. & $\mathrm{PZ}_{53} \mathrm{~T}_{47}$ & Calcium & 0 & 1 & 5 & 8 \\
\hline 2. & $\mathrm{PZ}_{52} \mathrm{~T}_{48}$ & Calcium & \multicolumn{2}{|c|}{2} & 6 & 10 \\
\hline 3. & $\mathrm{PZ}_{53} \mathrm{~T}_{47}$ & Strontium & 0 & 1 & 5 & 10 \\
\hline 4. & $\mathrm{PZ}_{56} \mathrm{~T}_{44}$ & Strontium & \multicolumn{2}{|c|}{12.5} & \multicolumn{2}{|c|}{20} \\
\hline 5. & $\mathrm{PZ}_{53} \mathrm{~T}_{47}$ & Barium & 0 & 2 & 4 & 6 \\
\hline 6. & $\mathrm{PZ}_{55} \mathrm{~T}_{45}$ & Samarium & 0 & 3 & 6 & 9 \\
\hline 7. & $\mathrm{PZ}_{52} \mathrm{~T}_{48}$ & Cadmium & 0 & 5 & 10 & 15 \\
\hline
\end{tabular}

Table.2.1 $T_{c}$ Values of MPB PZT Ceramics (continuation to Table 2)

\begin{tabular}{|c|c|c|c|c|}
\hline \multicolumn{4}{|c|}{$\mathbf{T}_{\mathrm{C}}\left(\sim^{\circ} \mathbf{C}\right)$} & \multirow{2}{*}{$\begin{array}{r}\text { Reference } \\
29\end{array}$} \\
\hline 385 & 385 & 385 & 360 & \\
\hline \multicolumn{2}{|c|}{325} & 315 & 300 & 30 \\
\hline 385 & 385 & 360 & 290 & 29 \\
\hline \multicolumn{2}{|c|}{265} & \multicolumn{2}{|c|}{242} & 29 \\
\hline 395 & 410 & 405 & 410 & 31 \\
\hline 390 & 352 & 349 & 320 & 32 \\
\hline 375 & 356 & 358 & 358 & Our sample \\
\hline
\end{tabular}

Table 3 presents the ionic radii (r) of the +2 valence modifiers and Table 4 shows ionic radii of +3 valence modifiers.

Table.3.' $r$ ' of +2 Valence Elements (http://abulafia.mt.ic.ac.uk/shannon/ptable.php )

\begin{tabular}{|l|l|l|}
\hline S.No & Element & $\mathbf{r}\left(\mathbf{x 1 0}^{-\mathbf{1 0}} \mathbf{m}\right)$ \\
\hline 1. & Calcium & 1 \\
\hline 2. & Strontium & 1.21 \\
\hline 3. & Barium & 1.38 \\
\hline 4. & Samarium & 1.22 \\
\hline
\end{tabular}


Table.4.' $r$ ' of +3 Valence Elements (credit: http://abulafia.mt.ic.ac.uk/shannon/ptable.php)

\begin{tabular}{|l|l|l|}
\hline S.No & Element & $\mathbf{r}\left(\mathbf{x 1 0}^{-\mathbf{1 0}} \mathbf{m}\right)$ \\
\hline 1. & Gallium & 0.76 \\
\hline 2. & Lanthanum & 1.032 \\
\hline 3. & Neodymium & 0.983 \\
\hline 4. & Dysprosium & 0.912 \\
\hline 5. & Bismuth & 1.03 \\
\hline 6. & Ytterbium & 0.868 \\
\hline 7. & Gadolinium & 0.938 \\
\hline
\end{tabular}

From Tables 3 and 4, it can be observed that the rvalue is lesser $(<1.04)$ and greater $(\geq 1)$ for +3 and +2 valence elements of coordination number 6 respectively. So the substitution of higher ionic radii elements will reduce the $T_{c}$ whereas the substitution of lower ionic radii elements can enhance the $T_{c}$. This may be due to the mismatch between ionic radii of substitute and substituent. In $\mathrm{PZT}, \mathrm{Pb}(\mathrm{r} \sim 0.98)$ atoms get replaced by modifier atoms due to the substitution at A-site. When ionic radii of both $\mathrm{Pb}$ and modifier ion are approximately similar, then the material may show the high $\mathrm{T}_{\mathrm{c}}$ values.

\section{Conclusions}

The samples of PCZT have been prepared by solid state synthesis. These ceramics are suggested for high $\mathrm{T}_{c}$ applications, due to their high $\mathrm{T}_{\mathrm{c}}$. The higher is the valence of a modifier, the greater is the $T_{c}$ value and vice versa. The higher is the ionic radius of a modifier, the lower is the $T_{c}$ value and vice versa. Therefore it is recommended that, to enhance the $\mathrm{T}_{\mathrm{c}}$ of MPB PZT, it is worth choosing a modifier whose ionic radius matches with lead ionic radius.

\section{Acknowledgement}

We (authors) are grateful for the experimental facilities provided by IIT Kharagpur. We also thak the partial financial support of DST-SERB.

\section{References}

[1] Panigrahi SC, Das PR, Padhee R andChoudhary RNP (2018). Effect of Gd on dielectric and piezoelectric properties of lead zirconatetitanate ferroelectric ceramics, Ferroelectrics, 524,14-29.

[2] Cherdhirunkorn B, Surakulananta S, Tangsritrakul J, Hall D andIntarasiri S (2020). The effect of nitrogen ion implantation on the physical and dielectric properties of cobalt-doped PZT ceramics, Results in Physics, 16, 102851.

[3] Zhang Q andWhatmore RW (2004). Low fatigue lead zirconatetitanate based capacitors modified by manganese for nonvolatile memories, Materials Science and Engineering B, 109, 136-140.

[4] Lee W, Kahya O, Tat Toh C, Ozyilmaz B and Hyun Ahn J (2013). Flexible graphene PZT ferroelectric nonvolatile memory, Nanotechnology,24,475202.

[5] Cheng C, Dangi A, Ren L, Tiwari S, Benoit R, Qiu Y, Lay HS, Agarwal S, Pratap R, Rajasekhar KS, Mallouk T, Cochran S andMcKinstry ST (2019). Thin film PZT Based PMUT Arrays for Deterministic Particle Manipulation. IEEE Transactions on Ultrasonics, Ferroelctrics and Frequency Control, 66, 1606-1615.

[6] Kusano Y, Qi Wang, Lou G, Lu Y, Rudy RQ, Polcawich RG and Horsley RG (2018).Effects of DC Bias Tuning on AirCoupled PZT Piezoelectric Micromachined Ultrasonic Transducers, Journal of Microelectromechanical Systems,27, 296304.

[7] Dong X, Yi Z, Kong L, Tian Y, Liu J and Yang B (2019).Design, Fabrication and Characterization of Bimorph Micromachined Harvester with Asymmetrical PZT Films, Journal of Microelectromechanical Systems, 28, 700706.

[8] Hu B, Wan J and Pang CK (2017).Head on Media Detection with PZT Self-Sensing Actuation in Dual-Stage Hard Disk Drives, IEEE Transactions on Magnetics, 53, 9400406.

[9] Kumar S and Jain YK (2015).Simulation of Circular-Shaped PZT-5H Sensor for Train Measurement Using COMSOL Multiphysics, IEEE Sensors Journal, 15, 4380-4387. 
[10]Kimura M and Ando A (2017). Chapter 2, Advanced Piezoelectric Materials, Springer.

[11]Feng $G$ and Lin Z (2011).Micromachined flexible diaphragm backed PZT ultrasonic transducer with a controllable self-focused acoustic beam, Meas. Sci. Technol., 22, 125204.

[12]Tiwari B, Babu T,Choudhary RNP (2020). Effect of Manganese Doping on Dielectric Characteristics of Lead ZirconateTitanate of Different Zirconium/Titanium Ratios, IOP Conference Series: Materials Science and Engineering, 764, 012029.

[13]Heywang W, Lubitz $\mathrm{K}$ and Wersing W (2008). Springer Series in Materials Science, Piezoelectricity, Springer.

[14]Tiwari B, Babu T,Choudhary RNP (2020). AC Impedance and Modulus Spectroscopic Studies of $\mathrm{Pb}\left(\mathrm{Zr}_{0.35-\mathrm{x}} \mathrm{Ce}_{\mathrm{x}} \mathrm{Ti}_{0.65}\right) \mathrm{O}_{3}(\mathrm{x}=0.00$, $0.05,0.10,0.15)$ Ferroelectric Ceramics, Materials Chemistry and Physics, 256, 123655.

[15]Tiwari B, Babu T,Choudhary RNP (2020).Synthesis

$\mathrm{Pb}\left(\mathrm{Zr}_{0.35-\mathrm{x}} \mathrm{Mn}_{\mathrm{x}} \mathrm{Ti}_{0.65}\right) \mathrm{O}_{3}, \mathrm{x}=0.00,0.02,0.06$, 0.10 ceramics and their structural, dielectric characteristics, Materials Research Express, 7, 055701.

[16]Tiwari B, Choudhary RNP (2010). Frequency-temperature response of $\mathrm{Ce}$ modified $\quad \mathrm{Pb}\left(\mathrm{Zr}_{0.65-\mathrm{x}} \mathrm{Ce}_{\mathrm{x}} \mathrm{Ti}_{0.35}\right) \mathrm{O}_{3}$ ferroelectric ceramics: Impedance spectroscopic studies, Journal of Alloys and Compounds, 4931:2, 1-10.

[17]Pradhan SK, Das SN, Bhuyan S, Behera C, Padhee R andChoudhary RNP (2016). Structural, dielectric and impedance characteristics of lanthanum-modified $\mathrm{BiFeO}_{3}-\mathrm{PbTiO}_{3}$ electronic system, Appl. Phys. A., 122, 604.

[18]KalpanaParida, Sujit Kumar Dehury andChoudhary RNP (2016).Structural, electrical and magneto-electric characteristics of complex multiferroic perovskite $\mathrm{Bi}_{0.5} \mathrm{~Pb}_{0.5} \mathrm{Fe}_{0.5} \mathrm{Ce}_{0.5} \mathrm{O}_{3}$, J Mater Sci: Mater Electron., 27, 11211.

[19]Das SN, Pattanaik A, Kadambini S, Pradhan S, Bhuyan S andChoudhary RNP (2016). Dielectric and impedance spectroscopy of $\mathrm{Ni}$ doped $\mathrm{BiFeO}_{3}-\mathrm{BaTiO}_{3}$ electronic system, J Mater Sci: Mater Electron, 27, 10099.

[20]Karapuzha AS, James NK, Khanbareh H, van der Zwaag S andGroen WA (2016), Structure, dielectric and piezoelectric properties of donor doped PZT ceramics across the phase diagram, Ferrolectrics, 504, 160-171.

[21]Sharma P, Hajra S, Sahoo S, Rout PK andChoudhary RNP(2017). Capacitive and resistive characteristics of gallium modified lead zirconatetitanate, J. Mater. Sci.: Mater. Electron.,28, 12048-12055.

[22]Sciyo (2010). Piezoelectric Ceramics,Elseveir publishers.

[23]Samanta S, Sankaranarayan V andSethupathi K (2018). Effect of $\mathrm{Nb}$ and $\mathrm{Fe}$ co-doping on microstructure, dielectric response, ferroelectricity and energy storage density of PLZT, J. Mater. Sci.: Mater. Electron.,29, 20383-20394.

[24]Perumal RN, Sadhasivam S andAthikesawan V (2019). Structural, dielectric, AC conductivity, piezoelectric and impedance spectroscopy studies on $\mathrm{PbZr}_{0.52} \mathrm{Ti}_{0.48} \mathrm{O}_{3}: \mathrm{RE}^{3+}\left(\mathrm{RE}^{3+}: \mathrm{La}^{3+}, \mathrm{Nd}^{3+}\right.$ and $\mathrm{Dy}^{3+}$ ) ceramics, Results in Physics, 15, 102729.

[25]Anil Babu T, Ramesh KV, Reddy VR and Sastry DL (2018).Structural and dielectric studies of excessive $\mathrm{Bi}^{3+}$ containing perovskite PZT and pyrochlore biphasic ceramics, Materials Science and Engineering B, 228, 175-182.

[26]Samad R, Rather MD, Asokan K and Want B (2018). Magneto-dielectric studies on multiferroic composites of $\mathrm{Pr}$ doped $\mathrm{CoFe}_{2} \mathrm{O}_{4}$ and $\mathrm{Yb}$ doped $\mathrm{PbZrTiO}_{3}$, Journal of Alloys and Compounds, 744, 453-462.

[27]Sharma S, Azad SC, Soaib Khan Md, Ranjan R, Behera B andChoudhary RNP (2014). Effect of $\mathrm{Gd}^{3+}$-substitution on structural and electrical properties of lead zirconatetitanate (PZT; $\mathrm{Zr} / \mathrm{Ti}=55 / 45)$ ceramics, J. Metallurgy and Materials Science, 56, 1-6.

[28]Rai R and Sharma S (2004). Structural and dielectric properties of $(\mathrm{La}, \mathrm{Bi})$ modified 
Communications, 129, 305-309.

[29]Kulscar F (1959). Electromechanical Properties of Lead TitanateZirconate Ceramics with Lead Partially Replaced by Calcium or Strontium, J. American Ceramic Society, 42(1), 49-51.

[30]Kour P, Kumar P, Sinha SK andKar M (2014). Electrical properties of calcium modified PZT (52/48) ceramics, Solid State Communications, 190, 33-39.

[31]Silva MM, Teixeira GF, Cavengo GF, Silva LL, Dias RG, Zaghete MA, Cilense M, Longo E and Cavalheiro AA (2014). Effects of The Addition of Ions Barium on The Structural and Electrical Properties of PZT Ceramic, Materials Science Forum, 798-799, 199-204.

[32]Ranjan R, Kumar R, Behera B and Choudhary RNP (2009). Effect of Sm on structural, dielectric and conductivity properties of PZT ceramics, Materials Chemistry and Physics, 115, 473-477. 